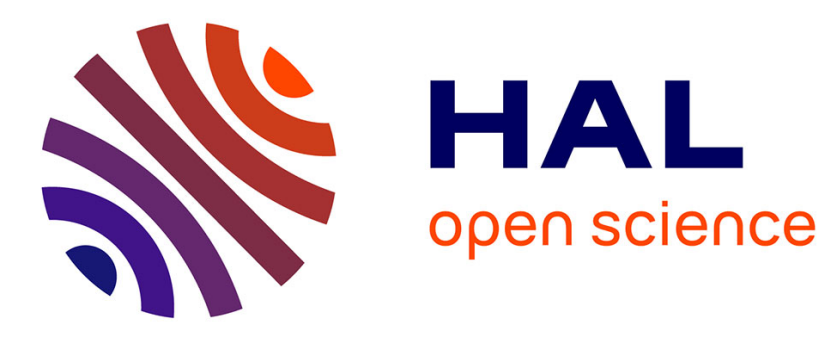

\title{
Enthalpy Relaxation in Phosphorus-Containing Dendrimers
}

Eric Dantras, Jany Dandurand, Colette Lacabanne, Anne-Marie Caminade, Jean Pierre Majoral

\section{- To cite this version:}

Eric Dantras, Jany Dandurand, Colette Lacabanne, Anne-Marie Caminade, Jean Pierre Majoral. Enthalpy Relaxation in Phosphorus-Containing Dendrimers. Macromolecules, 2002, 35 (6), pp.20902094. 10.1021/ma011228p . hal-01308056

\section{HAL Id: hal-01308056 https://hal.science/hal-01308056}

Submitted on 27 Apr 2016

HAL is a multi-disciplinary open access archive for the deposit and dissemination of scientific research documents, whether they are published or not. The documents may come from teaching and research institutions in France or abroad, or from public or private research centers.
L'archive ouverte pluridisciplinaire $\mathbf{H A L}$, est destinée au dépôt et à la diffusion de documents scientifiques de niveau recherche, publiés ou non, émanant des établissements d'enseignement et de recherche français ou étrangers, des laboratoires publics ou privés. 


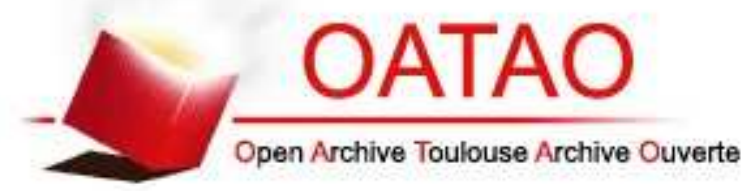

\section{Open Archive TOULOUSE Archive Ouverte (OATAO)}

OATAO is an open access repository that collects the work of Toulouse researchers and makes it freely available over the web where possible.

This is an author-deposited version published in : http://oatao.univ-toulouse.fr/ Eprints ID : 14314

To link to this article : DOI : 10.1016/ma011228p

URL : http://dx.doi.org/10.1021/ma011228p

To cite this version : Dantras, Eric and Dandurand, Jany and Lacabanne, Colette and Caminade, Anne-Marie and Majoral, JeanPierre Enthalpy Relaxation in Phosphorus-Containing Dendrimers. (2002) Macromolecules, vol. 35 ( $\mathrm{n}^{\circ}$ 6). pp. 2090-2094. ISSN 00249297

Any correspondance concerning this service should be sent to the repository administrator: staff-oatao@ listes-diff.inp-toulouse.fr 


\title{
Enthalpy Relaxation in Phosphorus-Containing Dendrimers
}

\author{
E. Dantras, J. Dandurand, and C. Lacabanne* \\ CIRIMAT, Laboratoire de Physique des Polymères, Université Paul Sabatier \\ 31062 Toulouse Cedex 04, France
}

\author{
A. M. Caminade and J. P. Majoral \\ Laboratoire de Chimie de Coordination, 31077 Toulouse Cedex 04, France
}

\begin{abstract}
A set of phosphorus-containing dendrimers involving five generations $(g=1-5)$ has been investigated using temperature-modulated calorimetry and standard differential scanning calorimetric techniques. The dendrimers show a complex glass transition temperature with a generation dependence. Enthalpy relaxations have been pointed out in this complex architecture macromolecule. Physical aging manifestations are studied vs complexity growth, with various cooling. The thermal manifestation intensity of physical aging decreases with generation.
\end{abstract}

\section{Introduction}

The molecular dynamic behavior of complex systems as dendrimers in the glassy state remains obscure. At low temperatures, below the glass transition temperature $T_{\mathrm{g}}$, relaxation processes and local motions are probably still possible. However, they would not be detected in differential scanning calorimetry experiments, except through physical aging processes. The aim of this study is to reveal this glassy state metastability phenomenon in dendrimers. Complex architecture influence on physical aging is also investigated.

Dendrimers are good models to study complex system, because they are characterized by a regularly branched treelike architecture: molecular structure complexity increases step by step as a function of generation (generation number $g$ ). And structural relaxation results correlated with Tool, Narayanaswamy, and Moynihan (TNM) model, give information on conformational rearrangements. A large number of studies have dealt with dielectric, ${ }^{1,2}$ rheologic, ${ }^{3,4}$ and optic ${ }^{5}$ properties of dendritic macromolecules (hyperbranched polymers and dendrimers), but there have been no investigations on physical aging in dendrimers. Yet, enthalpic manifestations appear in dendrimers. ${ }^{6}$ Standard differential scanning calorimetry permits one to analyze the evolution of glass transition temperature as a function of molecular weight, not only in cooling but also in heating rate. Furthermore, physical aging experiments have been carried out by standard DSC and compared with temperature-modulated DSC equivalent experiments. Impact of modulation on heat flow signal during a physical aging experiment is checked. Influence of the specific architecture of these sample on molecular mobility via enthalpic relaxation manifestation is studied. In this communication, we focus on low and middle generation from $g=1$ to $g=5$, of an amorphous phosphoruscontaining dendrimer.

\section{Experimental Section}

Materials and Sample Preparation. From a phosphorus core constituted by the strong $\mathrm{P}=\mathrm{S}$ dipole, these phosphorus-

\footnotetext{
* Corresponding author: E-mail: lacabane@cict.fr.
}

Table 1. Data for Phosphorus-Containing Dendrimers: $g$ Generation, $M_{\mathrm{w}}$ (Molecular Weight), and $\boldsymbol{n}_{\mathrm{e}}$ (Number of End Groups), Where $\Delta C_{p}$ Was Denoted by Standard DSC during the Cooling Scan with $q_{\mathrm{c}}=-20^{\circ} \mathrm{C} \cdot \mathbf{m i n}^{-1}$

\begin{tabular}{ccrc}
\hline generation $(g)$ & $M_{\mathrm{w}}\left(g \cdot \mathrm{mol}^{-1}\right)$ & $n_{\mathrm{e}}$ & $\Delta C_{p}\left(\mathrm{~J} \cdot \mathrm{g}^{-1} \cdot{ }^{\circ} \mathrm{C}^{-1}\right)$ \\
\hline 1 & 1423.4 & 6 & 0.35 \\
2 & 3417.3 & 12 & $(*)$ \\
3 & 7405 & 24 & 0.36 \\
4 & 15380 & 48 & 0.26 \\
5 & 31302 & 96 & 0.23
\end{tabular}

containing dendrimers were synthesized by a divergent process which consists of an iteration of chemical steps. On this same core, radially branched layers were attached (Figure 1). Dendrimers were synthesized generation after generation. Details of synthesis of this amorphous polymers were precisely described elsewhere. ${ }^{7,8}$ Numbering of these compounds hereafter will be done as follows: $\left[G_{d}^{\prime}\right]$ where $g$ is the number of generations-here $g=1$ to 5 - and $\mathrm{G}^{\prime}$ corresponds to dendrimers with terminal aldehyde end groups. They were quasimonodisperse with precise number of chain ends and monomer units (Table 1). All the studied samples are available as a powder. To maximize the signal, sample weights of 5-10 mg were used; the mass was low enough to allow the sample to follow the imposed thermal oscillations.

Standard and Temperature-Modulated Differential Scanning Calorimetry. Standard differential scanning calorimetry (DSC) and temperature-modulated differential scanning calorimetry (TMDSC) measurements were performed using a DSC/TMDSC 2920 setup manufactured by TA Instruments. The sample temperature was calibrated using the onset of melting of tin $\left(T_{\mathrm{m}}=231.88{ }^{\circ} \mathrm{C}\right)$, indium $\left(T_{\mathrm{m}}=156.6{ }^{\circ} \mathrm{C}\right)$ and cyclohexane $\left(T_{\mathrm{m}}=6{ }^{\circ} \mathrm{C}\right)$ with an heating rate of $q_{\mathrm{h}}=+5$ ${ }^{\circ} \mathrm{C} \cdot \mathrm{min}^{-1}$. The heat flow was calibrated with the heat of fusion of indium $\left(\Delta H=28.45 \mathrm{~J} \cdot \mathrm{g}^{-1}\right)$; its baseline was corrected with sapphire. DSC/TMDSC experiments were systematically carried out over a temperature range from the equilibrium state (in order to remove the effect of previous thermal history) $T_{\text {eq }}$ $=T_{\mathrm{g}}+20{ }^{\circ} \mathrm{C}$ down to the glassy state $T_{0}=T_{\mathrm{g}}-50{ }^{\circ} \mathrm{C}$ with a constant cooling rate $q_{\mathrm{c}}$, and followed by a linear or modulated heating rate $q_{\mathrm{h}}=+5{ }^{\circ} \mathrm{C} \cdot \mathrm{min}^{-1}$. For each sample, the glass transition temperature range but also the heat flow height were measured by standard DSC during a cooling scan (with $q_{\mathrm{c}}=-5{ }^{\circ} \mathrm{C} \cdot \mathrm{min}^{-1}$ or $q_{\mathrm{c}}=-20{ }^{\circ} \mathrm{C} \cdot \mathrm{min}^{-1}$ ). To point out the thermal manifestation of enthalpic relaxation, aging experiments were carried out by DSC and also by TMDSC. Samples were frozen from $T_{\text {eq }}$ down to $T_{0}$ with various linear cooling rates $\left(0.1^{\circ} \mathrm{C} \cdot \mathrm{min}^{-1} \leq\left|q_{\mathrm{c}}\right| \leq 40^{\circ} \mathrm{C} \cdot \mathrm{min}^{-1}\right)$. The heat flow rate was recorded with a linear heating rate (DSC experiments) 



Figure 1. Schema of phosphorus-containing dendrimer architecture (points $(\bullet)$ symbolize $\mathrm{P}=\mathrm{S}$ groups) and molecular structure of $g=1$ and 2 (respectively $\left[G_{1}^{\prime}\right]$ and $\left[G_{2}^{\prime}\right]$ ).

and also during a temperature amplitude modulation (TMDSC experiments) of $\pm 1{ }^{\circ} \mathrm{C}$ every period oscillation of $60 \mathrm{~s}(f \sim 17$ $\mathrm{mHz}$ ), with both $q_{\mathrm{h}}=+5{ }^{\circ} \mathrm{C} \cdot \mathrm{min}^{-1}$. The fictive temperature $T_{\mathrm{f}}$ can be calculated from enthalpy data ${ }^{14}$

$$
\int_{T_{\mathrm{f}}}^{T^{*}}\left(C_{p_{\mathrm{l}}}(T)-C_{p_{\mathrm{g}}}(T)\right) \mathrm{d} T=\int_{T}^{T^{*}}\left(C_{p}(T)-C_{p_{\mathrm{g}}}(T)\right) \mathrm{d} T
$$

where $C_{P_{1}}$ and $C_{P_{\mathrm{g}}}$ are the extrapolated heat capacity of the liquid and the glassy state respectively, $T^{*}$ is a temperature above the glass transition, and $T^{*}>T$. In the glassy state, well below the transition region

$$
\lim _{T \ll T_{\mathrm{g}}} T_{\mathrm{f}}=T_{\mathrm{f}}
$$

where $T_{\mathrm{f}}$ is the limiting value of $T_{\mathrm{f}}$ obtained when the glass is cooled through the transition region at a fixed cooling rate $q_{\mathrm{c}}$. Tool's ${ }^{12-14}$ method, $T_{\mathrm{g}} \equiv T_{\mathrm{f}}$, is preferred to midpoint method as regards experimental errors. The principle of TMDSC experiments ${ }^{9}$ is that a sinusoidal temperature change is superimposed on the linear temperature program. The temperature $T_{\mathrm{S}}$, measured at the sample position, is governed by

$$
T_{S}=T_{0}+\left\langle q_{\mathrm{h}}\right\rangle t-\frac{\left\langle q_{\mathrm{h}}\right\rangle C_{\mathrm{S}}}{K}+A_{T_{\mathrm{S}}} \sin (w t+\epsilon)
$$

the average marked \langle\rangle is always taken over one modulation cycle, so that the modulation effect becomes zero. $T_{0}$ is the temperature at time $t=0 ;\left\langle q_{\mathrm{h}}\right\rangle$, the underlying, constant scanning rate; $C_{S}$, the heat capacity of the sample calorimeter (sample + pan); $K$, the Newton law constant; $A_{T_{\mathrm{S}}}$ the amplitude of temperature modulation; $w$, the modulation frequency in $\mathrm{rad} \cdot \mathrm{s}^{-1}$; and $\epsilon$, the phase lag relative to a reference oscillation. The "zero" of the phase lag has been chosen at $T_{0}$ and $T_{\text {eq }}$, well below and above the glass transition range. The modulated heat flow signal, $\dot{Q}$, is averaged to obtain the total heat flow signal, $\langle\dot{Q}\rangle$, equivalent to a normal DSC experiment. ${ }^{12} \mathrm{~A}$ discrete Fourier transform ${ }^{13}$ permits one to extract an in-phase signal $\langle\dot{Q}\rangle_{\text {IN }}$ (called "reversing signal"), to the cyclic response. The out of phase signal, $\langle\dot{Q}\rangle_{\text {Out, }}$, (also called "nonreversing signal") is obtained by subtracting the in-phase contribution to the total heat flow. Deconvolution of the complex heat flow offers a better method for separating the glass transition from the associated relaxation. Then, TMDSC is particularly well suited to the study of physical aging in polymeric materials.

\section{Results}

Limiting Fictive Temperature. Glass transition temperature evolution is followed upon generation (Figure 2); a standard differential scanning calorimeter was used. The glass transition temperature ranges vs $g$ have been estimated by this classical method and they were reported with the specific heat step $\Delta C_{p}$ in Table 1. $\Delta C_{p}$ decreases upon generation: from $0.35(g=1)$ to $0.23 \mathrm{~J} \cdot \mathrm{g}^{-1} \cdot{ }^{\circ} \mathrm{C}^{-1}(g=5)$. For $g=2$, the width of the glass



Figure 2. Heating standard DSC experiments with $q_{\mathrm{h}}=+5$ ${ }^{\circ} \mathrm{C} \cdot \mathrm{min}^{-1}$ after a cooling with $q_{\mathrm{c}}=-0.1{ }^{\circ} \mathrm{C} \cdot \mathrm{min}^{-1}$ for different generation $\left(\triangle\right.$ for $\left[G_{1}^{\prime}\right], \square$ for $\left[G_{3}^{\prime}\right]$, and $\diamond$ for $\left.\left[G_{5}^{\prime}\right]\right)$.

Table 2. Limiting Fictive Temperature $\left(\boldsymbol{T}_{\mathrm{g}} \equiv T_{\mathrm{f}}\right)$ with $\boldsymbol{q}_{\mathrm{c}}=-0.1^{\circ} \mathrm{C} \cdot \mathrm{min}^{-1}$ and $\boldsymbol{q}_{\mathrm{c}}=-5^{\circ} \mathrm{C} \cdot \mathrm{min}^{-1}$ for $\left[G_{1}^{\prime}\right]$, [ $\left.G_{3}^{\prime}\right]$, and $\left[G_{5}^{\prime}\right]$. and Values of $\Delta \boldsymbol{h}^{*}$ for $\left[G_{1}^{\prime}\right],\left[G_{3}^{\prime}\right]$ and $\left[G_{5}^{\prime}\right]$

\begin{tabular}{llll}
\hline generation $(g)$ & 1 & 3 & 5 \\
$T_{\mathrm{f}}\left(q_{\mathrm{c}}=-0.1^{\circ} \mathrm{C} \cdot \mathrm{min}^{-1}\right)\left({ }^{\circ} \mathrm{C}\right)$ & 65.05 & 110.35 & 134.25 \\
$T_{\mathrm{f}}\left(q_{\mathrm{c}}=-5{ }^{\circ} \mathrm{C} \cdot \mathrm{min}^{-1}\right)\left({ }^{\circ} \mathrm{C}\right)$ & 74.75 & 116.45 & 140.15 \\
$\Delta h^{*}\left(\mathrm{~kJ} \cdot \mathrm{mol}^{-1}\right)$ & $142 \pm 10$ & $253 \pm 18$ & $247 \pm 16$
\end{tabular}

transition range increases and experimental errors make the determination of $\Delta C_{p}$ critical (denoted by an asterisk in Table 1). The temperature dependence of the fictive temperature $T_{\mathrm{f}}$ has been used for defining a limiting fictive temperature $T_{\mathrm{f}}$, characteristic of the physical state of the glass. For quenched samples, $T_{\mathrm{f}} \equiv$ $T_{\mathrm{g}}$ as defined by standard DSC. Thanks to Tool's procedure, the $T_{\mathrm{f}}$ values for generations $g=1,3$ and 5 have been calculated upon a series of various cooling (from $\mathrm{q}_{\mathrm{c}}=-0.05$ to $-40{ }^{\circ} \mathrm{C} \cdot \mathrm{min}^{-1}$ ). For $q_{\mathrm{c}}=-0.1$ and $-5{ }^{\circ} \mathrm{C} \cdot \mathrm{min}^{-1}, T_{\mathrm{f}}$ results have been reported in Table 2 . $T_{\mathrm{g}}$ increases from $74.75(g=1)$ to $140.15^{\circ} \mathrm{C}(g=5)$ with $\left|q_{\mathrm{c}}\right|=\left|q_{\mathrm{h}}\right|=5^{\circ} \mathrm{C} \cdot \mathrm{min}^{-1}$.

Heat Capacity. $\Delta C_{p}$ and $T_{\mathrm{g}}$ evolutions are opposite, when $g$ increases. $\Delta C_{p}$ values are function of macromolecules freedom degree number; $T_{\mathrm{g}}$ is linked to molecular weight and rigidity of chain backbone. These results show that the generation plays a leading part in the mobility of dendrimers. Phosphorus-containing dendrimers evolve from a fragile thermodynamic behavior $\left(\Delta C_{p} \geq 0.3 \mathrm{~J} \cdot \mathrm{g}^{\left.-1 .{ }^{\circ} \mathrm{C}^{-1}\right)}\right.$ at lower $g$, to a stronger one at upper $g$. Global molecular mobility decreases with 


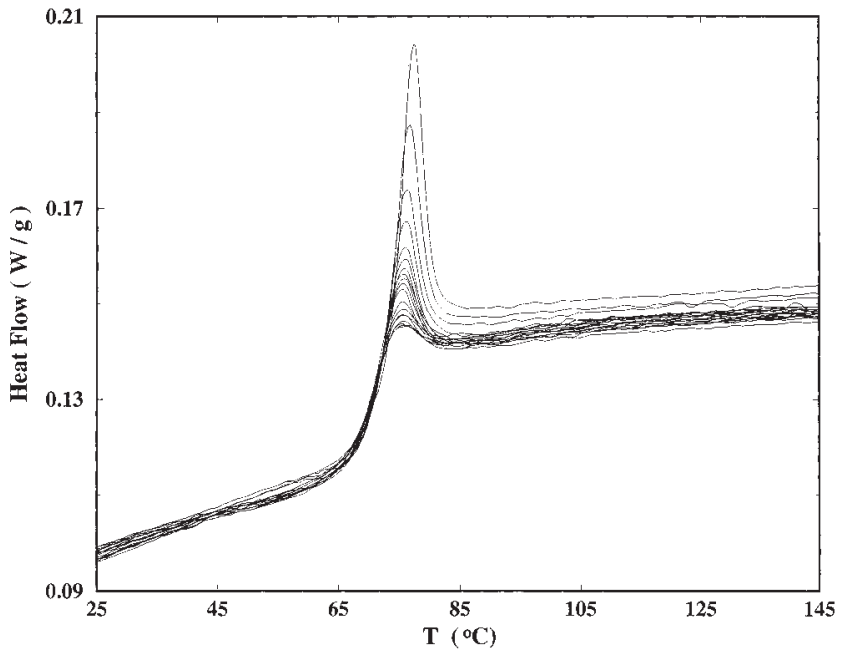

Figure 3. Heating standard DSC experiments for $\left[G_{1}^{\prime}\right]$ after various cooling rates $\left(0.1^{\circ} \mathrm{C} \cdot \mathrm{min}^{-1}<\left|q_{\mathrm{c}}\right|<5^{\circ} \mathrm{C} \cdot \mathrm{min}^{-1}\right)$.

Table 3. $\Delta H$ Values and Maximum Intensities $I_{1}$ Deduced from Integration of Two $Q\left(T, q_{\mathrm{c}}\right)$ Scans $\left(q_{\mathrm{c}}=-5{ }^{\circ} \mathrm{C} \cdot \mathrm{min}^{-1}\right.$ and $\left.q_{\mathrm{c}}=-0.1^{\circ} \mathrm{C} \cdot \mathrm{min}^{-1}\right)$

$\begin{array}{llll}\text { generation }(g) & 1 & 3 & 5 \\ A\left(\mathrm{~J} \cdot \mathrm{g}^{-1}\right) & 0.188 & 0.110 & 0.075 \\ I_{2}\left(\mathrm{~mW} \cdot \mathrm{g}^{-1}\right) & 44.7 & 11.4 & 12\end{array}$

generation. The $C_{p}(T)$ curves are measured in heating scans after different thermal history (in order to point out enthalpy relaxation $\left.q_{\mathrm{c}} \leq-5{ }^{\circ} \mathrm{C} \cdot \mathrm{min}^{-1}\right)$. The effect of the cooling rate is the same that in amorphous polymers: an endothermic peak is superimposed on the classical $C_{p}$ step inherent to the glass transition. When the cooling rate decreases, the height of the peak increases (Figure 3). This thermal manifestation is characteristic of physical interactions disruption, that ensure the cohesion of the glassy state. Furthermore, an evolution in the heat flow right side value is noted as a function of $q_{\mathrm{c}}$. A slight increase of the right side stage from 0.143 to $0.151 \mathrm{~W} \cdot \mathrm{g}^{-1}$ is observed. It could be interpreted by the existence of residual physical interactions above $T_{\mathrm{g}}$ (probably until $T_{\mathrm{eq}}$ ).

Enthalpy. The enthalpy recovery during the aging process is determined by integration of two scans ${ }^{15}\left(q_{\mathrm{c}}\right.$ $=-5$ and $-0.1{ }^{\circ} \mathrm{C} \cdot \mathrm{min}^{-1}$ )

$$
\Delta H=\int_{T}\left[Q\left(T, q_{\mathrm{cl}}\right)-Q\left(T, q_{\mathrm{c} 2}\right)\right] \mathrm{d} T
$$

where

$$
\Delta Q\left(T, q_{\mathrm{c}}\right)=Q\left(T, q_{\mathrm{c} 1}\right)-Q\left(T, q_{\mathrm{c} 2}\right) \geq 0
$$

with $Q\left(T, q_{\mathrm{c} 1}\right)$ and $Q\left(T, q_{\mathrm{c} 2}\right)$ being, respectively, the heat flow for $q_{\mathrm{c}}=-0.1$ and $-5{ }^{\circ} \mathrm{C} \cdot \mathrm{min}^{-1} . \Delta Q\left(T, q_{\mathrm{c}}\right) \geq 0$ is an arbitrary choice. The maximum $I_{1}$ of the difference of the two scans was defined by

$$
I_{1}=\left\{Q\left(T, q_{\mathrm{c} 1}\right)-Q\left(T, q_{\mathrm{c} 2}\right)\right\}_{\max }
$$

The results have been reported in Table 3. $\Delta H$ and $I_{1}$ decrease clearly with generation. The limiting fictive temperature, ${ }^{12} T_{\mathrm{f}}$, is related to the cooling rate (Figure 4), $q_{\mathrm{c}}$, by

$$
\frac{\mathrm{d}\left(\ln \left|q_{\mathrm{c}}\right|\right)}{\mathrm{d}\left(\frac{1}{T_{\mathrm{f}}}\right)}=-\frac{\Delta h^{*}}{R}
$$

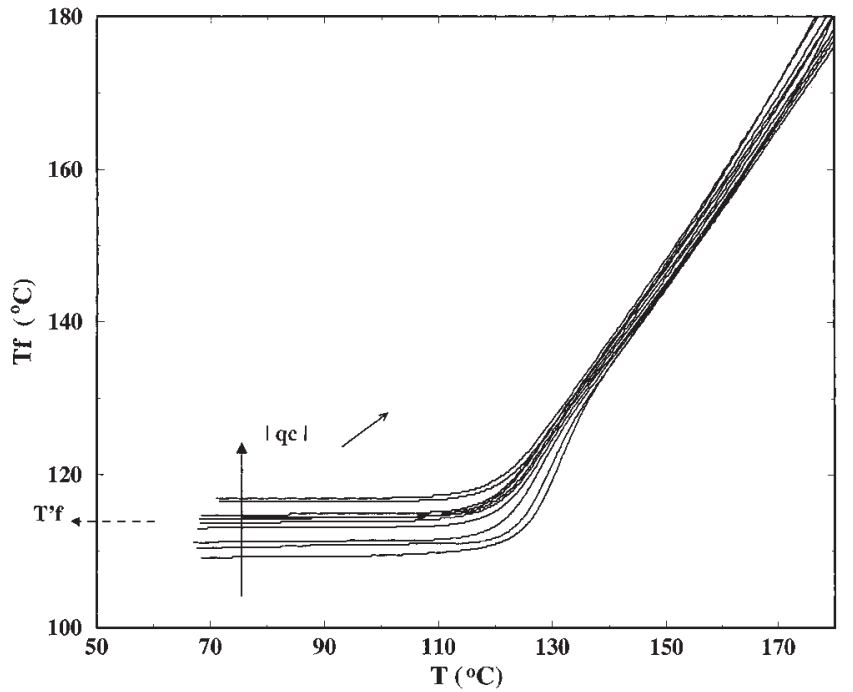

Figure 4. Fictive temperature $T_{\mathrm{f}_{\mathrm{exp}}}$ vs temperature upon cooling rates.

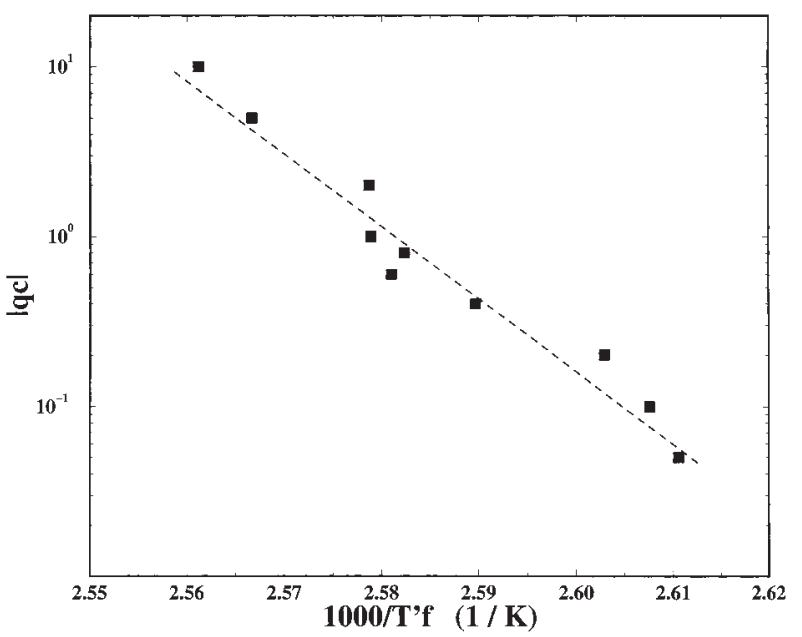

Figure 5. Logarithm of $\left|q_{\mathrm{c}}\right|$ vs reciprocal $T_{\mathrm{f}}$ for $\left[G_{3}^{\prime}\right]$.

where $R$ is the universal gas constant and $\Delta h^{*}$ the activation enthalpy for the relaxation times controlling the structural relaxation. In Figure 5, the logarithm of $\left|q_{\mathrm{c}}\right|$ is plotted vs $1 / T_{\mathrm{f}}$ for the generation $g=3$. As expected from eq 7 , when $\Delta h^{*}$ is temperature-independent, the plot is linear. Thanks to cooling experiments $\Delta h^{*}$ has been calculated and values are reported in Table 2 as a function of generation. $\Delta h^{*}$ values increase from approximately 140 to $250 \mathrm{~kJ} \cdot \mathrm{mol}^{-1}$ when $g$ increases from $g=1$ to $g=3,5$. Taking into account experimental errors, generations 3 and 5 do not exhibit significant variations in terms of Tool analysis. In fact, error bars given in Table 2 are fit errors and not experimental errors. Three decades of cooling rate are necessary to fit eq 7 .

TMDSC has been also used for studying enthalpic relaxations. ${ }^{16}$ In Figure 6a, we present the TMDSC raw data obtained from the generation $g=1$ with a linear cooling rate $q_{\mathrm{c}}=-0.1^{\circ} \mathrm{C} \cdot \mathrm{min}^{-1}$. The results are shown in Figure 6b, where the three curves represent the inphase signal, the total heat flow, and the out-of-phase signal. The glass transition occurs in the in-phase component, while the enthalpic relaxation manifestation that occurs during this transition appear only in the outof-phase component. The enthalpic relaxation can be 



Figure 6. TMDSC raw data obtained for the generation $\left[G_{1}^{\prime}\right]$ : (a) before discrete Fourier transform (DFT) analysis; (b) after DFT. Key: (O) for the total heat flow $\langle\dot{Q}\rangle,(\square)$ for the inphase signal $\left\langle\dot{Q}_{\mathrm{IN}}\right\rangle$, and $(\Delta)$ for the out-of-phase signal $\left\langle\dot{Q}_{\mathrm{OUT}}\right\rangle$.

Table 4. $A$ Values and Maximum Intensities $I_{2}$ Deduced from Integration of Two $\langle\dot{Q}\rangle_{\text {OUT }}\left(T, q_{\mathrm{c}}\right)$ Scans $\left(q_{\mathrm{c}}=-5\right.$ ${ }^{\circ} \mathrm{C} \cdot \min ^{-1}$ and $\left.q_{\mathrm{c}}=-0.1{ }^{\circ} \mathrm{C} \cdot \mathrm{min}^{-1}\right)$

$\begin{array}{llll}\text { generation }(g) & 1 & 3 & 5 \\ A\left(\mathrm{~J} \cdot \mathrm{g}^{-1}\right) & 0.189 & 0.143 & 0.087 \\ I_{2}\left(\mathrm{~mW} \cdot \mathrm{g}^{-1}\right) & 30 & 18.4 & 10.5\end{array}$

calculated using the out-of-phase heat flow signal, $\langle\dot{Q}\rangle_{\text {ouT: }}$

$$
A=\int_{T}\left[\langle\dot{Q}\rangle_{\mathrm{OUT}}\left(T, q_{\mathrm{c} 1}\right)-\langle\dot{Q}\rangle_{\mathrm{OUT}}\left(T, q_{\mathrm{c} 2}\right)\right] \mathrm{d} T
$$

where

$$
\begin{aligned}
\Delta\langle\dot{Q}\rangle_{\mathrm{OUT}}\left(T, q_{\mathrm{c}}\right)=\langle\dot{Q}\rangle_{\mathrm{OUT}}\left(T, q_{\mathrm{c} 1}\right)- \\
\langle\dot{Q}\rangle_{\mathrm{OUT}}\left(T, q_{\mathrm{c} 2}\right) \geq 0
\end{aligned}
$$

with $\langle\dot{Q}\rangle_{\text {OUT }}\left(T, q_{\mathrm{c} 1}\right)$ and $\langle\dot{Q}\rangle_{\mathrm{OUT}}\left(T, q_{\mathrm{c} 2}\right)$ being the out-ofphase component of the phase lag corrected heat flow for, respectively, $q_{\mathrm{c}}=-0.1$ and $-5{ }^{\circ} \mathrm{C} \cdot \mathrm{min}^{-1}$. The maximum $I_{2}$ of the difference of two scans is defined by

$$
I_{2}=\left\{\langle\dot{Q}\rangle_{\mathrm{OUT}}\left(T, q_{\mathrm{c} 1}\right)-\langle\dot{Q}\rangle_{\mathrm{OUT}}\left(T, q_{\mathrm{c} 2}\right)\right\}_{\max }
$$

Results have been reported in Table 4 . Note that $A$ and $I_{2}$ decrease also with generation, from $g=1$ to $g=5$. Modulation influence on physical aging can be responsible for slight difference between $A$ value, in the case of $g=1$ and $g=3$.

\section{Discussion}

The combined standard DSC and TMDSC studies show the metastability of the physical structure of amorphous dendrimers. The influence of thermal history on phosphorus-containing dendrimers has been analyzed by standard DSC using the classical protocol of Narayanaswamy and Moynihan. Upon increasing aging, the endothermic peak increases and the limiting fictive temperature $T_{\mathrm{f}}$ decreases. These evolutions are qualitatively analogous with the ones reported in linear polymers. ${ }^{17}$ It is important to note that $T_{\mathrm{f}}$ is an increasing function of generation. From a practical point of view, this result means that the higher generations dendrimers have a higher rigidity. Contrarily the activation enthalpy of physical aging, $\Delta h^{*}$, is not significantly dependent upon generation. Note that the values of $\Delta h^{*}$ are the half of the ones reported for linear polymers. ${ }^{17}$

The values of enthalpy as defined by standard DSC or TMDSC have been found perfectly coherent: both decrease significantly when the generation increases. This decrease of the out-of-phase phenomena is accompanied by a decrease of the in-phase effect (heat capacity step). Both phenomena are governed by the cohesion of the amorphous phase. It is interesting to report here the results of de Gennes and Hervet ${ }^{18}$ on the statistics of "starburst polymers" prepared by Tomalia. ${ }^{19}$

Thanks to a modified version of the Edwards selfconsistent field, they found theoretically that a dense packing effect restricts the growth to a limiting generation number $\left(m_{1}\right)$. The ideal starburst growth is restricted to a number of generations $m \leq m_{1}$ with

$$
m_{1}=2.88 \times \ln P+4.4 \pm 0.2
$$

where $P$ (spacers) is the number of flexible units between two connected branch points. Poly(amidoamine) dendrimers and phosphorus-containing dendrimers are different upon chemical composition, but both architectures are analogous: coordination number 3 for cross-links. For each generation the system is fully reacted, and there is no segregation trends between cross-links and spacers. Experimental determination of $m_{1}$ for phosphorus-containing dendrimers with aldehyde end groups gives $m_{1}=11$. These dendrimers probably follow the same statistic as starburst polymers. Moreover, it is interesting to draw a parallel between dense packing effect and the decrease of physical aging. The ultimate step of molecular mobility giving rise to the vanishing of physical aging in phosphorus-containing dendrimers might be the dense packing effect.

\section{Conclusion}

The growth of phosphorus-containing dendrimers has been performed until generation 11 . It is interesting to note that such a limiting value to ideal growth can be estimated from a modified version of the Edwards selfconsistent field method proposed by de Gennes and Hervet for starburst polymers. Then, we can accept a restriction to molecular mobility upon increasing generation in our dendrimers.

Calorimetric studies by standard DSC and temperature-modulated DSC confirm this prediction. Indeed, for low generations $(1,2$, and 3$)$ the molecular mobility give rise to a physical aging that decreases upon increasing $g$. For higher generations, physical aging has vanished probably due to the dense packing effect phenomenon. Like in linear polymers, the limiting fictive temperature may be used for characterizing the physical structure 
of dendrimers. Note that for quenched samples, it is coherent with the glass transition temperature as measured by standard DSC.

\section{References and Notes}

(1) Trahasch, B.; Stuhn, B.; Frey, H.; Lorenz, K. Macromolecules 1999, 32, 1962-1966.

(2) Huwe, A.; Appelhans, D.; Prigann, J.; Voit, B. I.; Kremer, F. Macromolecules 2000, 33, 3762-3766.

(3) Jahromi, S.; Palmen, J. H. M.; Steeman, P. A. M. Macromolecules 2000, 33, 577-581.

(4) Srinivas, U.; Morrison, F. A.; Dvornic, P. R. Macromolecules 2000, 33, 2551-2560.

(5) Matos, M. S.; Hofkens, J.; Verheijen, W.; De Schryver, F. C.; Hecht, S.; Pollak, K. W.; Fréchet, J. M. J.; Forier, B.; Dehaen, W. Macromolecules 2000, 33, 2967-2973.

(6) Dantras, E.; Caminade, A. M.; Majoral, J. P.; Lacabanne, C.; Macromolecules 2001, 34, 3808-3811.

(7) Lartigue, M. L.; Donnadieu, B.; Galliot, G.; Caminade, A.M.; Majoral, J.-P.; Fayet, J.-P. Macromolecules 1997, 30, $7335-7337$.

(8) Majoral, J.-P.; Caminade, A.-M. Topics in Current Chemistry, Springer Verlag: Berlin, Heidelberg, 1998; Vol. 197, pp 79124.
(9) Reading, M.; Elliot, D.; Hill, V. L. J. Therm. Anal. 1993, 40, 949-955.

(10) Hutchinson, J. M.; Montserrat, S. Thermochim. Acta 1997 304/305, 257-265

(11) Wunderlich, B.; Boiler, A.; Okazaki, I.; Ishikiriyama, K. Thermochim. Acta 1997, 304/305, 125-136.

(12) Moynihan, C. T.; Easteal, A. J.; De Bolt, M. A.; Tucker, J. J. Am. Ceram. Soc. 1976, 59, 12-16.

(13) Tools, A. Q. J. Am. Ceram. Soc. 1946, 29, 240-253.

(14) Narayanaswamy, O. S. J. Am. Ceram. Soc. 1971, 54, 491498.

(15) Alegria, A.; Guerrica-Echevarría, E.; Goitiandía, L.; Telleria, I.; Colmenero, J.; Macromolecules 1995, 28, 1516-1527.

(16) Wang, Y.; Song, R.; Shen, D. J. Macromol. Sci.-Phys. 1998. B37, 709-716.

(17) Bacharan, C. Thesis, Paul Sabatier University, Toulouse, France, 1999.

(18) de Gennes, P. G.; Hervet, H. J. Phys. Lett. 1983, 44, 351360.

(19) Tomalia, D. A.; Baker, H.; Dewald, J.; Hall, M.; Kallos, G.; Martin, S.; Roeck, J.; Ryder, J.; Smith, P. Polym. J. 1985, 17, $177-132$. 